\title{
Review of research trend in international construction projects: a bibliometric analysis
}

\author{
Wahyudi Utama, Albert Chan, Hafiz Zahoor and Ran Gao \\ Department of Building and Real Estate, Hong Kong Polytechnic University, Hong Kong
}

\begin{abstract}
This paper presents the latest research development in international construction project (ICP) domain from 1995 to 2014 as revealed in the construction management related journals. A systematic document retrieval method was employed to collect relevant articles. The identified papers were analyzed by using bibliometric analysis comprising the investigation of the number of publication, the main originators of the research contributions, their affiliations, the most cited papers, and the sources of research funding as well as the research methods used. Ninetyeight relevant articles obtained from 12 major journals associated with construction management studies were successfully assessed. The results show an upward trend with some fluctuations during the period and the bibliometric information of ICP studies was successfully presented.
\end{abstract}

Keywords: International construction project, research trend, review, bibliometric.

Paper type: Viewpoint

\section{Introduction}

During the last two decades, many issues and challenges have arisen related to international construction project (ICP) activities. Scholars in the construction area have thus been attracted to observe the phenomena, explore methods and practices, study the experiences and performances to find solutions that would better the burgeoning international construction industry. Their contributions offer a significant enrichment to the treasury of construction management body of knowledge and encourage an improvement of management and technical practices.

Although an undoubted interest dominates the exploration of the ICP area, a further review and analysis of the trends revealed in previous studies, so far, appears to have been overlooked. Therefore the aim of this paper is to systematically analyze the findings of relevant manuscripts published in some selected journals. The objectives are to map the ICP studies and to identify their active contributors, including their countries and research center origin, citation count, and the common research methods adopted in the ICP studies.

\section{International construction projects studies}

Starting an overseas construction project is not as simple as beginning other types of industrial projects such as manufacturing (Kim, Ashuri and Han, 2013). Considerations necessary before an overseas construction project can take place tend to be more numerous and complex. Conditions in the targeted country will be very different to those of the home country (Ling, Ibbs and Kumaraswamy, 2005). Examples include those such as the different behaviour of laborers and the use of different plant. The results on site are therefore likely to be unpredictable

Copyright: Construction Economics and Building 2016. C 2016 Wahyudi P. Utama, Albert P.C. Chan, Hafiz Zahoor and Ran Gao. This is an Open Access article distributed under the terms of the Creative Commons Attribution 4.0 Unported (CC BY 4.0) License (https://creativecommons.org/licenses/by/4.0/), allowing third parties to copy and redistribute the material in any medium or format and to remix, transform, and build upon the material for any purpose, even commercially, provided the original work is properly cited and states its license.

Citation: Utama, W.P., Chan, A.P.C., Zahoor, H and Gao, R. 2016. Review of research trend in international construction projects: a bibliometric analysis, Construction Economics and Building, 16(2), 71-82. DOI: http://dx.doi.org/10.5130/AJCEB.v16i2.4866.

Corresponding author: Wahyudi P. Utama; Email - wahyudi.utama@connect.polyu.hk

Publisher: University of Technology Sydney (UTS) ePress 
and associated with often incalculable problems on a massive scale. Many types of risks and uncertainties however have now been identified, assessed and reviewed (Hastak and Shaked, 2000; Chan and Tse, 2003; Ozorhon et al., 2008). Additionally, carrying out overseas construction projects may considerably impact the structure of the company in areas such as management, financial organization, and utilization of advanced technology (Hawk, 2006; Tang, Atkinson and Zou, 2012). Hence it is of little surprise that the penetration of an overseas market is obviously a strategic decision but fiercely underlain by robust motivation.

The international construction business, as indicated above, is rapidly evolving. However, it is important to draw attention to the necessity and difficulty in defining the term "international construction" which is universally acceptable when used in international discussion (Mawhinney, 2001). To date, this term has not yet reached a consensus among either researchers or practitioners. Nonetheless, Mawhinney's definition of "international construction" namely, "where one company, resident in one country, performs work in another country" has been cited by numerous researchers such as Gunhan (2003) and Ngowi et al. (2005).

Initially, discourses on capability, management and competence (Jaafari, 1984; Simkoko, 1992), political risks, measure and management (Ashley and Bonner, 1987), trend of client needs and future competition (Halpin, 1990), future prediction (Bon, 1992), contractor's future comparison between countries (Abdul-Aziz, 1994), expansion motivation (Ashley and Bonner, 1987; AbdulAziz, 1991), and performance of the contractor from specific country (Arditi and Gutierrez, 1991) all present subjects relevant to the conduct of international construction studies. It is of note that in the early years of the second millennium, research into international construction has begun to reach the area for which business and financial, as well as the manufacturing industry, explored two decades ago.

Financial risk management, for instance is a theory now adopted to develop a procedural framework for selecting international construction projects based on the overall prospective company's profit maximization on a certain receivable risk (Han et al., 2004). Similarly, interdisciplinary theories such as cross impact analysis (Han and Diekmann, 2001b), organizational memory or knowledge management (Ozorhon, Dikmen and Birgonul, 2006), causal relationship between project profit and risk (Han et al., 2007), investment financial evaluation (Kim, Ashuri and Han, 2013), entry mode and business strategy (Chen and Messner, 2011) have become a familiar topic in the construction realm. Unexpectedly, ICP research also promoted the application of artificial intelligence (Dikmen and Birgonul, 2004), a technique which manufacturing industry has already extensively explored.

\section{Methodology}

To conduct the study presented in this paper, a hierarchical analysis method with the objective of retrieving, selecting and reviewing previous research outputs of particular domain was adopted. This method which was also employed in studies by Yi and Chan (2013) and Osei-Kyei and Chan (2015) for a similar objectives, were adopted. The process is shown in Figure 1.

\section{Identification of scholarly manuscripts}

By using a similar technique as for web search engine, identification of journals was comprehensively carried out. Specific keywords were entered into the Scopus and WOS search engines. These databases are the most frequently exploited for searching academic references and are considered the world's most widespread scholarly manuscripts databank covering various disciplines (Guz and Rushchitsky, 2009). In addition, the two databases are commonly used as a publication barometer for journals regarding quantity and impact (Aghaei Chadegani et al., 2013). A search encryption was set to find relevant articles. It comprised related words or phrases under 
the title/abstract/keyword such as; international construction projects, overseas construction projects, international projects, overseas projects, international construction markets, overseas construction markets. A complete search encryption for the Scopus machine is given as follows:

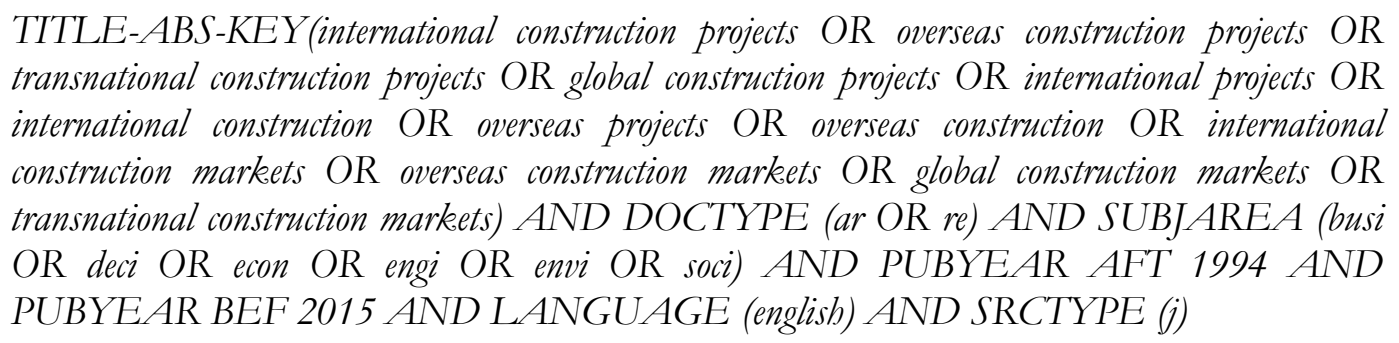

The same procedure was repeated using the WOS engine tailored to meet requirements. Three filters were set (e.g. year, language and type of source) to ensure that it captured and met the demand.

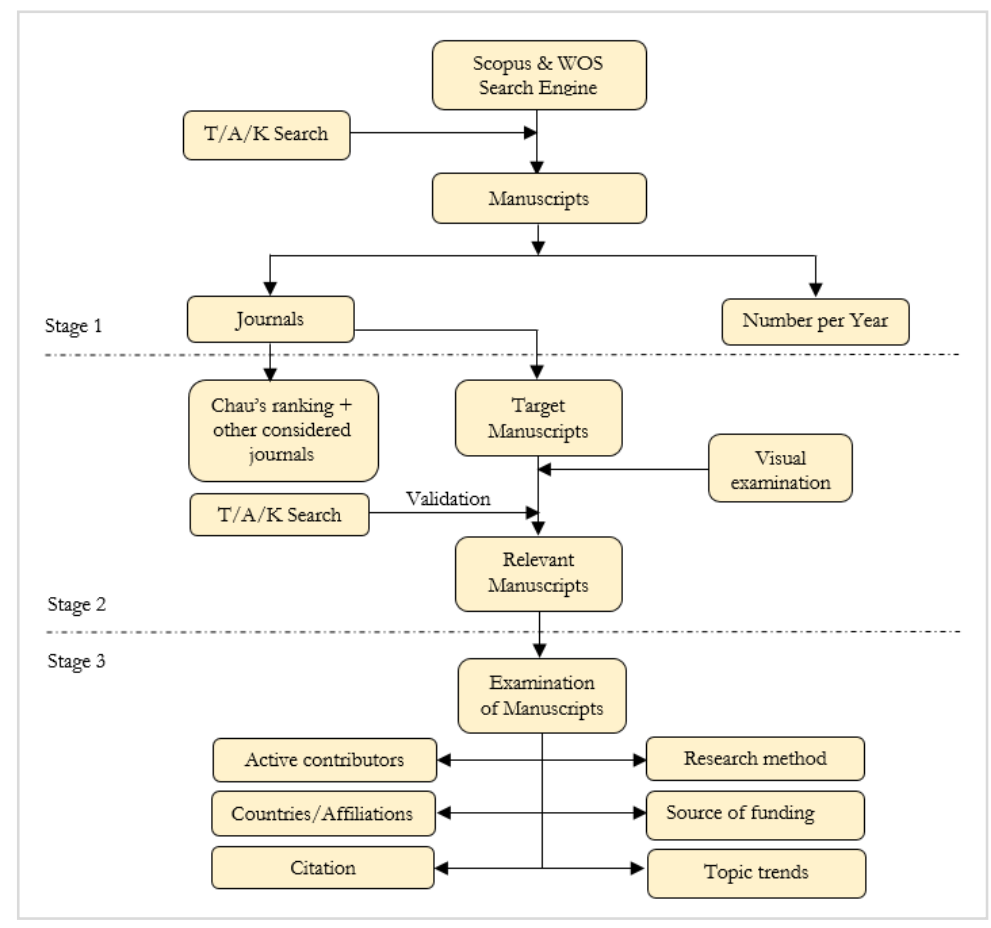

Figure 1: The search process

(Source: Modified from Osei-Kyei and Chan (2015); Note: T/A/K - title/abstract/keywords)

\section{Selection of target scholarly manuscripts}

The difficulty of selecting appropriate journals however should be noted. Selection decisions are based on subjective judgment, frequently affected by the experience of authors (Holt, 2010). It is therefore top peer reviewed construction management journals highly recommended by most academic communities in this field that were selected, based on a study by Chau (1997). Although Chau's study was completed over 18 years ago, to date it is still relevant in the domain of Construction Management. The journals mentioned in his study were used in several new papers including two studies mentioned in the beginning of Methodology section. As a result, 82 and 76 manuscripts were found in Scopus and WOS respectively spread over 12 selected journals.

Further examination of the above results indicates 57 and 58 relevant manuscripts from Scopus and WOS respectively. It is worth noting that some academic manuscripts appeared twice in 
both databases, so careful scrutiny is necessary to avoid double accounting. As a result, 98 relevant manuscripts are provided from 12 selected journals. Hence the average of research output issued equal to almost five titles per year during the period 1995-2014. The statistical data of the whole process conducted in stage 2 is presented in Table 1.

Table 1: Search result of manuscripts on ICP in selected journals.

\begin{tabular}{|c|c|c|c|c|c|c|c|c|}
\hline & & SCOPUS & & & WOS & & Reviewed & $\%$ \\
\hline Journal Name & Tracked & Relevant & $\%$ & Tracked & Relevant & $\%$ & & \\
\hline $\begin{array}{l}\text { Construction Management and } \\
\text { Economics (CME) }\end{array}$ & 15 & 13 & 86.67 & NA & - & - & 13 & 13.27 \\
\hline $\begin{array}{l}\text { Journal of Construction Engineering } \\
\text { and Management (JCEM) }\end{array}$ & 32 & 25 & 78.13 & 29 & 25 & 86.21 & 40 & 40.82 \\
\hline $\begin{array}{l}\text { Engineering Construction and } \\
\text { Architectural Management (ECAM) }\end{array}$ & 3 & 2 & 66.67 & NA & - & - & 2 & 2.04 \\
\hline $\begin{array}{l}\text { Journal of Management in } \\
\text { Engineering (JME) }\end{array}$ & 12 & 6 & 50.00 & 12 & 14 & 116.67 & 17 & 17.35 \\
\hline $\begin{array}{l}\text { International Journal of Project } \\
\text { Management (IJPM) }\end{array}$ & 7 & 4 & 57.14 & 8 & 1 & 12.50 & 5 & 5.10 \\
\hline Automation in Construction (AIC) & 3 & 2 & 66.67 & 5 & 3 & 60.00 & 3 & 3.06 \\
\hline $\begin{array}{l}\text { Building Research Information } \\
\text { (BRI) }\end{array}$ & 1 & - & - & 4 & 3 & 75.00 & 3 & 3.06 \\
\hline $\begin{array}{l}\text { Journal of Professional Issues in } \\
\text { Engineering Education and Practice } \\
\text { (JPIEEP) }\end{array}$ & 1 & 1 & 100 & 7 & 5 & 71.43 & 5 & 5.10 \\
\hline $\begin{array}{l}\text { Canadian Journal of Civil } \\
\text { Engineering (CJCE) }\end{array}$ & 2 & 2 & 100 & 5 & 5 & 100 & 5 & 5.10 \\
\hline Habitat International (HI) & 3 & 1 & 33.33 & 4 & 4 & 100 & 4 & 4.08 \\
\hline $\begin{array}{l}\text { International Journal of } \\
\text { Construction Management (IJCM) }\end{array}$ & 2 & - & - & NA & - & - & - & - \\
\hline $\begin{array}{l}\text { Australasian Journal of Construction } \\
\text { Economics and Building (AJCEB) }\end{array}$ & 1 & 1 & 100 & NA & - & - & 1 & 1.02 \\
\hline Total & 82 & 57 & 69.51 & 74 & 60 & 81.08 & 98 & 100 \\
\hline
\end{tabular}

\section{Assessment of target manuscripts}

The assessment of each of the selected manuscripts required a quantitative analysis of their annual contribution, the author's origin, country, research center, number of citations and research focus area. An orthodox issue assessing main authors' contributions however has been the subject of debate among several researchers, each from various areas (Yuan and Shen, 2011). One of two methods used to measure an individual author's contribution in a multi-authored paper, and broadly adopted, is a formula initiated by Howard, Cole and Maxwell, (1987). The formula is given below:

Score $=\frac{1.5^{n-i}}{\sum_{i=1}^{n} 1.5^{n-i}}$

where $n$ is the number of authors in the manuscript; and $i$ is the ordinal number of the specific author.

In addition an in depth analysis was carried out to examine the development trend in the ICP research domain. The reasons for this work are based in the need to map the research methods employed and to find research topic trends. The research methods mapped embraces kinds of research (qualitative, quantitative and mixed mode); primary type of data collection (survey, case study, review and experiment) and data analysis techniques (theoretical analysis, descriptive analysis, statistical analysis and model development or simulation). In addition to the above, the identification of research topic in the area of ICP encompasses the highly related subjects groups including, (1) risk management and assessment, (2) entry mode and global strategy, (3) critical success factors, (4) competition advantages and performance, (5) international projects in specific countries, and (6) decision making topic. 


\section{Results and discussions}

\section{Annual trend of research output on ICP from 1995 to 2014}

Preliminary retrieval of data from Scopus and WOS journal databases on ICP manuscripts produced 210 and 730 articles respectively. These appear in numerous journals published from 1995 to 2014. Of interest is, that after in-depth review of the manuscripts in the selected journals, only 98 manuscripts were truly relevant to ICP studies (refer to Table 1). The statistical trend of annual number of relevant publications from 1995 to 2014 of selected journals is shown in Figure 2.

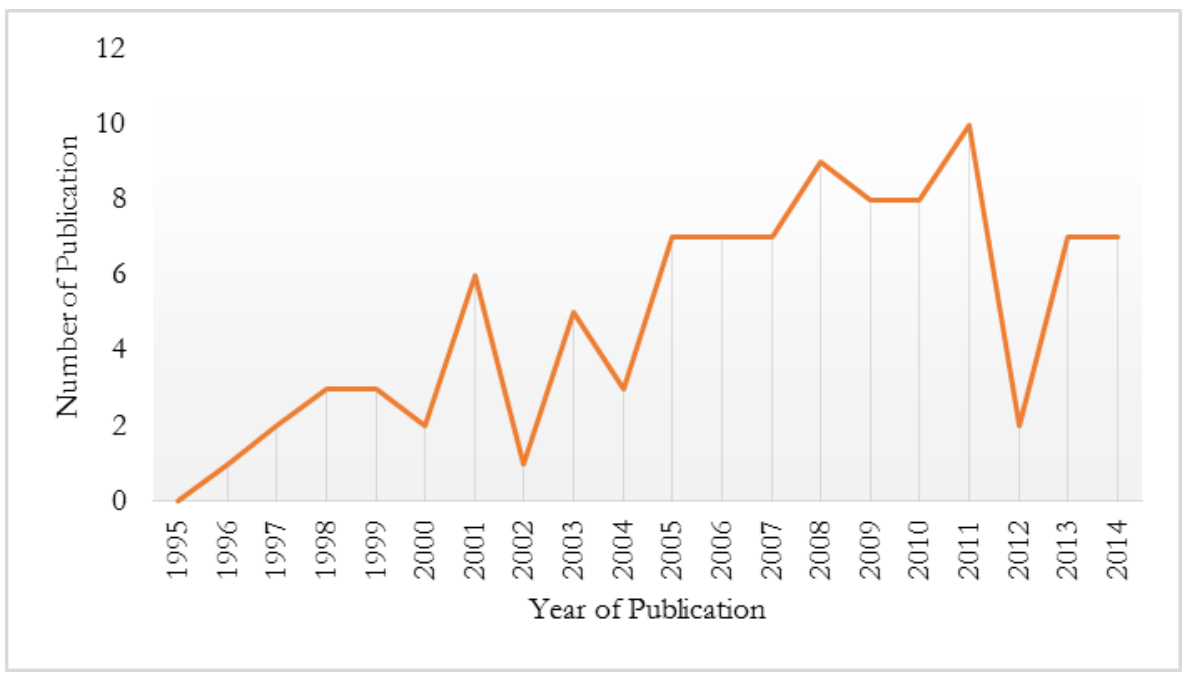

Figure 2: Trend of research output of ICP studies in selected journals

It is clear from the line graph shown in Figure 2 that the research output trends in ICP studies fluctuated over the years from 1995 to 2014. During this period, the number of publications increased substantially over four periods (i.e. 2000-2001; 2002-2003; 2004-2005 and 2012-2013), and sharply plunged in two periods (i.e. 2001-2002 and 2011-2012). Furthermore, in first six years spent tracing the trends, production of academic papers rose slowly with a total of eleven articles published. However it dramatically climbed to six articles in one year, later. In contrast, the years from 2004 to 2011 can be said as to be seen as fruitful ICP issues research years. Fifty six academic papers were published over an eight year period, with an average of seven per year. Unfortunately, at the end of the trend, the number of articles dropped abruptly from 10 to two titles in one year. However it swiftly rebounded to seven titles in the following year.

\section{Active contributors to the publication}

Of 98 manuscripts published from 1995 to 2014, fifteen researchers each actively contributed to the propagation of ICP study. Each researcher contributed more than two articles (Table 2). The contribution score of each author was measured by using formula (1). The score obtained by an author of one paper was then added to that achieve by the publication of other papers. For instance Jung published three articles. In the first paper he was $4^{\text {th }}$ author of a group of five, while in the second paper, he was $1^{\text {st }}$ author of four and the $1^{\text {st }}$ author of three in the third paper. These figures give the total contribution score of Jung as $0.11+0.42+0.47=1.00$.

Of the data given in above table, the first point to note is that the major contributors in 15 ICP researchers from 12 research centers and from 7 countries have each produced at least three papers. The total score of those authors is 33.80 , meaning that they have contributed almost 35 percent of a total 98 manuscripts. Furthermore, of the score 33.80 point contributed by authors mentioned above, the top five authors have yielded a total of around 55.80 percent. The most 
prolific contributor is Han, S.H. from Yonsei University, South Korea. Collectively Korean authors have a total score of 8.64 point. Surprisingly Turkey, as the only developing country in the list, posts three authors in the top five, coming from two different research centers. Jointly they contribute a score of 7.80. Of interest is that the United States, the largest developed country, presents a score of 6.20 points contributed by four authors, each from different research centers. The authors from the above countries cooperatively contribute approximately 67 percent of total score of all publications.

Table 2: Active contributors to more than two articles

\begin{tabular}{lclll}
\hline \multicolumn{1}{c}{ Authors } & $\begin{array}{c}\text { Number } \\
\text { of articles }\end{array}$ & \multicolumn{1}{c}{ Research Center } & \multicolumn{1}{c}{ Country } & Score \\
\hline Han, S.H. & 13 & Yonsei University & South Korea & 5.38 \\
Dikmen, I. & 13 & Middle East Technical Univ. & Turkey & 4.55 \\
Birgonul, M.T. & 14 & Middle East Technical Univ. & Turkey & 3.23 \\
Ling, F.Y.Y. & 9 & National University of Singapore & Singapore & 3.08 \\
Ozorhon, B. & 6 & Bogazici Univ. & Turkey & 2.62 \\
Kim, D. & 7 & Yonsei University & South Korea & 2.26 \\
Arditi, D. & 6 & Illinois Institute of Technology & USA & 1.92 \\
Chen, C. & 3 & University of Melbourne & Australia & 1.80 \\
Lu, W. & 4 & University of Hong Kong & Hong Kong & 1.68 \\
Messner, J. & 4 & The Pennsylvania State Univ. & US & 1.60 \\
Diekmann, J.E. & 4 & University of Colorado & US & 1.40 \\
Ibbs, C.W. & 4 & University of California & US & 1.28 \\
Shen, L.Y. & 4 & The Hong Kong Polytechnic Univ. & Hong Kong & 1.18 \\
Jung, W. & 3 & Yonsei University & South Korea & 1.00 \\
Flanagan, R. & 3 & University of Reading & UK & 0.82 \\
\hline
\end{tabular}

In general, the greater the number of articles, the higher the score obtained. Table 2 shows that Han has the highest score, with 13 publications even though the largest contributor of published articles is Birgonul with 14 papers. Other examples, consistent with the above, affirm that the greater the number of article does not automatically significantly increase the score. Indeed, there is an effect on the score if the author has many publications. The position of writers in the given list of authors of a paper and number of authors who collaborate in a research output are the main factors considered when calculating individual author's scores.

By the same token, the score of research origin of the relevant ICP manuscripts was found as presented in Table 3. The score of the country where the paper originated was also determined based on Formula 1. Hence a tally of the authors based on their authorship order in each published article, the paper accumulation score of each author from the same nation becomes the score for their country of origin. For instance, a paper resulting from the accumulation of the collaboration of Ling (Singapore), Ibbs (US) and Chew (Singapore), gives a country origin score for Singapore as 0.68 points. These points are obtained from the accumulation of contribution by Ling (0.47) and Chew (0.21), while the US gains 0.32 from Ibbs as second author in the paper.

As indicated above, Table 3 provides information about ICP manuscripts, country of origin, together with the number of institutions involved, articles published and participating researchers. During the period 1995-2014, 130 authors from 46 research center in 10 major nations have actively participated in encouraging ICP research as a means of contributing to a body of knowledge. The aggregate score achieved by those countries is 87.97 with 63.25 percent of the sum coming from five main nations. The table also shows that the developed countries such as Singapore, US, Hong Kong, South Korea, UK and Australia, actively play an important role in promoting ICP studies. Unpredictably Turkey, as an emerging economic nation, overtakes some developing countries and posts a ranking of three. In addition it is important to note that some researchers from China, India and Malaysia started to show an interest in exploring this research domain. 
Table 3: Country origin of ICP manuscripts published with at least 2 score point

\begin{tabular}{lcccc}
\hline \multirow{2}{*}{ Country } & \multicolumn{3}{c}{ Number of } & \multirow{2}{*}{ Score } \\
\cline { 2 - 4 } & Institution & Papers & Researcher & \\
\hline Singapore & 5 & 15 & 25 & 15.17 \\
USA & 9 & 12 & 19 & 14.60 \\
Turkey & 3 & 13 & 13 & 12.49 \\
Hong Kong & 3 & 10 & 23 & 10.51 \\
South Korea & 5 & 8 & 14 & 10.48 \\
UK & 7 & 9 & 16 & 9.77 \\
Australia & 6 & 7 & 10 & 6.82 \\
Malaysia & 2 & 3 & 3 & 3.00 \\
China & 4 & 4 & 4 & 2.93 \\
India & 2 & 3 & 3 & 2.20 \\
\hline
\end{tabular}

Table 4: Most frequently cited papers at least 50 times

\begin{tabular}{lccc}
\hline \multicolumn{1}{c}{ Authors } & Year & Journal & Cited \\
\hline Shen, L., Wu, G. and Ng, C. & 2001 & JCEM & 204 \\
Hastak, M. and Shaked, A. & 2000 & JME & 197 \\
Wang, S.Q., Dulaimi, M.F. and Aguria, M.Y. & 2004 & CME & 186 \\
Han, S. and Diekmann, J. & 2001 & JCEM & 180 \\
Dikmen, I. and Birgonul, M.T. & 2006 & CJCE & 175 \\
Bing, L., Tiong, R., Fan, W. and Chew, D. & 1999 & JCEM & 169 \\
Gunhan, S. and Arditi, D. & $2005 b$ & JCEM & 146 \\
Chan, E.H.W. and Tse, R. & 2003 & JCEM & 143 \\
Raftery, J., Pasadilla, B., Chiang, Y.H., Hui, E.C.M. and Tang, B.S. & 1998 & CME & 141 \\
Crosthwaite, D. & 2000 & BRI & 108 \\
Bing, L. and Tiong, R. & 1999 & JCEM & 100 \\
Sui Pheng, L. and Hongbin, J. & 2003 & JCEM & 84 \\
Mohamed, S. & 2003 & JCEM & 83 \\
Loosemore, M. and Muslmani, H.S.A. & 1999 & IJPM & 79 \\
Dikmen, I. and Birgonul, M. & 2004 & JCEM & 76 \\
Han, S., Diekmann, J. and Ock, J. & 2005 & JCEM & 74 \\
Ling, F.Y.Y., Ibbs, C.W. and Cuervo, J.C. & 2005 & CME & 74 \\
Momaya, K. and Selby, K. & 1998 & CJCE & 73 \\
Han, S., Park, S., Kim, D., Kim, H., and Kang, Y. & 2008 & AIC & 70 \\
Han, S.H. and Diekmann, J.E. & 2001 & CME & 69 \\
Dikmen, I., Birgonul, M.T. and Gur, A.K. & 2007 & AIC & 63 \\
Ozorhon, B., Arditi, D., Dikmen, I. and Birgonul, M. & 2008 & JCEM & 62 \\
Javernick-Will, A. and Levitt, R.E. & 2010 & JCEM & 60 \\
Dikmen, I. and Birgonul, M.T. & 2004 & JCEM & 57 \\
Gunhan, S. and Arditi, D. & $2005 a$ & JCEM & 56 \\
Zhao, Z., Shen, L. and Zuo, J. & 2009 & JCEM & 51 \\
Kapila, P. and Hendrickson, C & 2001 & JME & 51 \\
Ozorhon, B., Dikmen, I. and Birgonul, M.T. & 2007 & JME & 50 \\
\hline
\end{tabular}

(Source: Google Scholar (https://scholar.google.com.hk/) accessed on Oct 10 $\left.{ }^{\text {th }}, 2015\right)$

Other important information related to the analysis of research trends is revealed by the citation count. Generally all journal data bases, including ones such as Scopus and WOS, provide such information. However both these databases gave different information about this matter. For example a manuscript published by Shen, Wu and Ng, (2001) in JCEM has been cited 103 times according to Scopus, but according to WOS has been cited 68 times. Another popular academic search engine, Google Scholar was therefore utilized to deal with this ambiguity. The results show only seven out of 11 journals with 28 articles contribute to the list. Those journals contribute to a citation count 2,881 times, equal to a count of 102.89 cited times on average. Furthermore, JCEM with 15 papers on the list reported 1,548 citation hits equal to 53.63 percent of total citation and hence becoming the most influential journal in ICP studies. Interestingly, in this journal, an article by Shen, Wu and Ng, published in 2011, also appears to have had strong impact in terms of reference abstracted by the research community. Although Chau's 1997 study did not take CJCE into account in his assessment journal, the paper by Dikmen and Birgonul 
(2006) published in this journal is noted to be in the top five of the most frequently cited papers in the list. In total this journal collected 248 citations or 8.61 percent citation count with 2 articles. Further detail is shown in Table 4.

\section{Research methodology employed}

Through comprehensive review on research methodology in each manuscript, classification of methods was made. Survey techniques including distribution of questionnaires, interview and field observation are favourite methods in ICP research. This indication is that they enable most researchers to find the kind of data and its source. This method is sometimes accompanied by interviews to support issues from the respondents' point of view (e.g. Ling, Ibbs and Kumaraswamy (2005) and Abdul-Aziz and Wong (2010). The hybrid method refers to two or three data collection method employed in the same time. Such method can be found in such as Zhang (2011) who had combined questionnaire survey and case studies and Lu, et al. (2009) with data gleaned from company's reports, interviews, seminars and interactions with respondents. In very limited samples, experiment methods were found in studies by Jung et al. (2010), Jung, Han and Lee (2012), Kapila and Hendrickson (2001) and Han, Diekmann and Ock (2005).

As mentioned above, the descriptive analysis method was found to be used in almost half of the total 98 relevant papers. Descriptive analysis could mean statistical description which enables researchers to use many types of data with a few indices to indicate their intentions (Gay, Mills and Airasian, 2011). This analysis may be a form of a developed description based on objective or subjective opinion such as SWOT (strength-weakness-opportunity-treat) analysis. This study highlights a modelling technique such as used by Jung, Han and Lee (2012) and simulation such as in Kim, Ashuri and Han, (2013) as an approach to significantly increase the number of publications. A number of tools, both analytical, such as cross-impact analysis (Han and Diekmann, 2001a) and analytical hierarchy process (Gunhan and Arditi, 2005a; 2005b), and artificial such as neuro-net has been utilized in ICP studies.

Figure 3 shows the distribution of manuscripts which fall into three categories in terms of similarity of research method, data collection and data analysis method. The figure clearly illustrates that quantitative research, survey method for data acquisition, and descriptive analysis style, are the scientific methods steering part of ICP research papers.

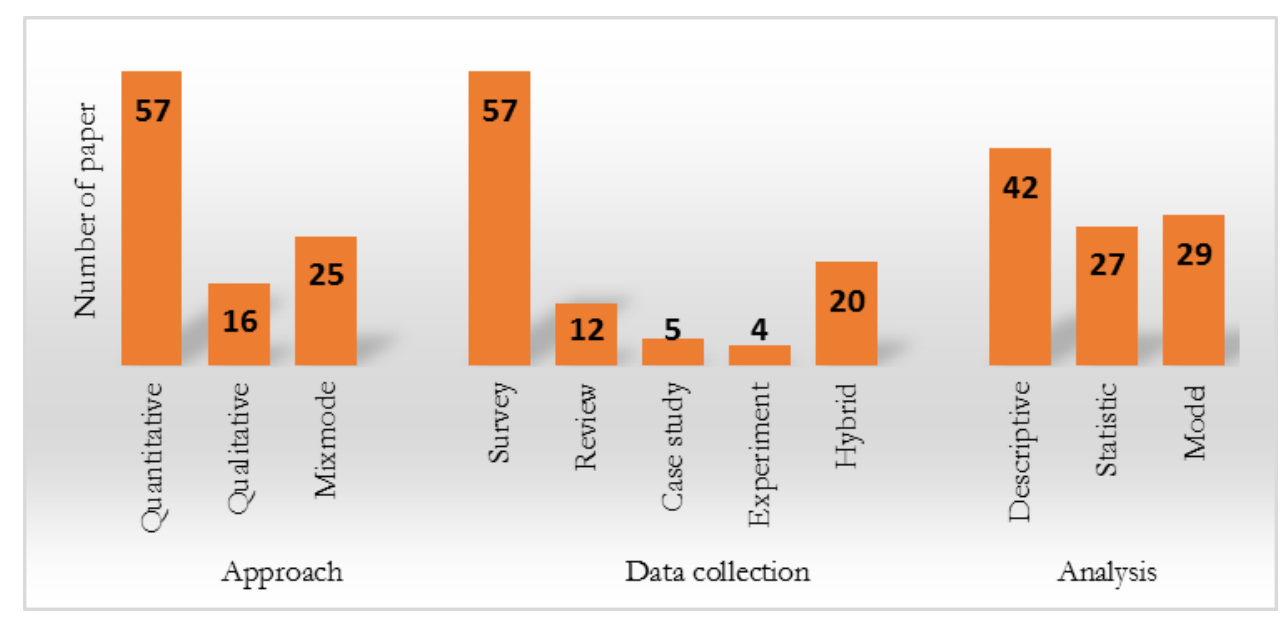

Figure 3: Trends of research methodology employed in ICP studies 


\section{The sources of research funding}

Though the sources of research funding are excluded in bibliometric studies, this paper propagates this figure to provide information about the role of research sponsors in research projects. Figure 4 presents the role of sponsors' institution in supporting research of ICP. Generally speaking the government, through its agencies and departments, plays a central role in supporting research projects in many countries. In this study, the government dominantly contributed in providing research funds for about $60 \%$ of ICP papers mentioning their grant resources. In contrast, the Industry and University's contribution were just over $6 \%$ and $23 \%$ respectively. Overall, over a third of ICP articles mentioned the sources of research funding in their acknowledgement part, while there was no such information explicitly stated in the rest.



Figure 4: The sources of research funding

\section{Trends of research topic}

To figure out the evolution of ICP research topics from 1995 to 2014, firstly they are categorized into six closely related interests namely 1) industrial development, 2) risk management and assessment, 3) global and entry strategy, 4) critical success factors and barriers, 5) competition and performance, and 6) knowledge-management and decision making. Subjectivity in deciding and categorizing the area of research under specific topics may be unavoidable (Ke et al., 2009). However through comprehensive reading of articles, particularly the associated discussion may significantly eliminate any divergence in notion. To simplify the timeframe, the period is then divided into four terms as shown in Figure 4.

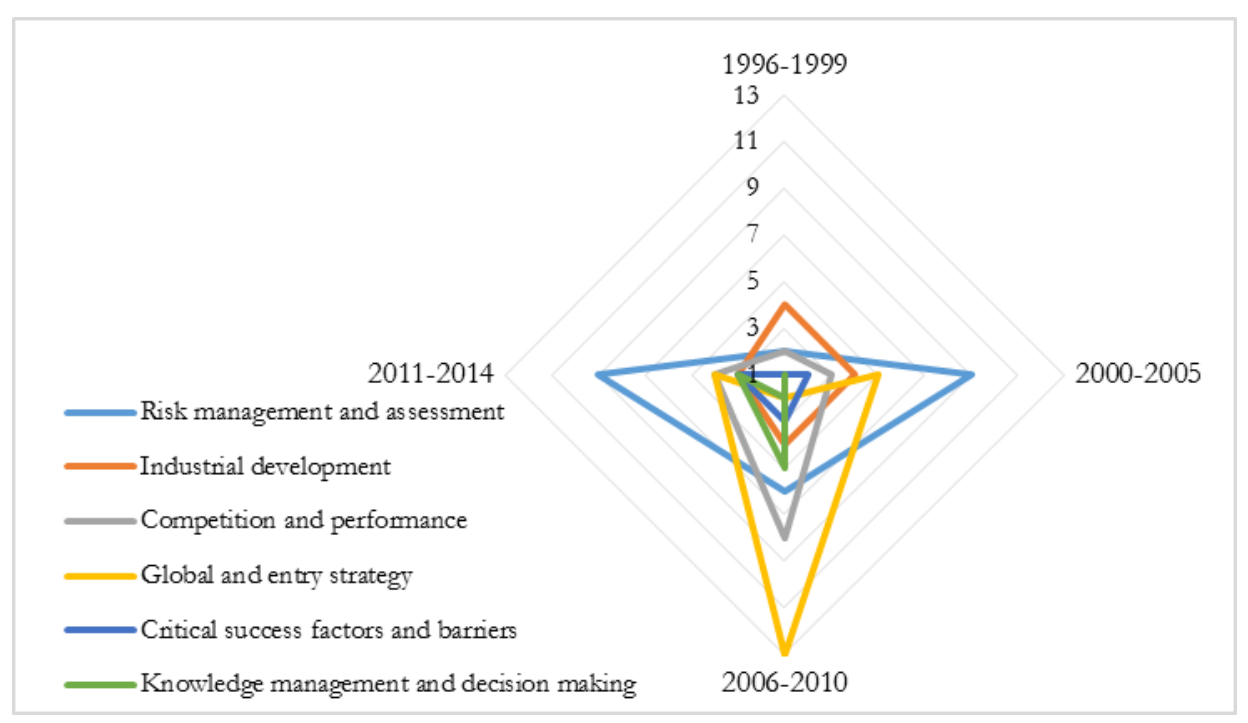

Figure 5: The development of ICP research topic 
Figure 5 depicts how research topics in ICP changed during the period 1994-2014. The first point to note is that there are three different topics which attract researchers' concern in particular. In the first term, the area related to Industrial development (e.g. industry structure, regional construction markets, future market trends, etc.) piqued researchers' interest. The trends changed to Risk management fields (e.g. risk identification, risk analysis, risk evaluation, and political risk, social risk, and financial risk, etc.) in the second and repeated again in the last term. The Global and entry strategy topics (e.g. internationalization, entry mode, business, marketing and growth strategy, alliances and collaboration, etc.) interrupted the trends in the third term.

Interestingly, Risk management topics remained relatively steady for about eight to nine papers in the last three terms. While the topic of Global and entry strategy surprisingly became the most favourable topic in term 2006-2010, this phenomenon abruptly decreased in the following term. Similarly in the same term, researchers seemed quite interested in the topic of Competition and performance (e.g. international competition and competitiveness, countries and industry performance, etc.) and Knowledge management and decision making (e.g. lesson-learnt from experiences, decision making model, market and project selection), this attention reduced substantially in term 2011-2014. Compared to the five mentioned topics, the area of Critical success factors and barriers (e.g. critical success factors, project success, obstacle and factors affecting international projects, etc.) tended to be overlooked in all terms. This area offers important issues for further research direction, together with knowledge management and decision making topics.

\section{Conclusion}

This paper set out to present the research output development from an ICP knowledge published in the last two decades (1995-2014). A growing interest in ICP studies over the last 20 years was the initial impression from the results, although the trend did show some fluctuation in terms of the quantity. ICP research must parallel with the development of related industries in which the developed countries have played a central role for many years. As a result, the active contributors in supplying analytical thinking and critical ideas are also dominated by researchers from centres of excellence in advanced developed countries such as South Korea, the US and Singapore. However the contributions of the Turkish research teams are far from minimal. This study also found a strong interest from researchers in further developing countries such as China, Malaysia and India. The citation count, as an impact parameter of a publication, and based on Google Scholar, records an article written by Shen's team from the Hong Kong Polytechnic University as the most widely referenced in this domain. In addition, the Journal of Construction Engineering and Management (JCEM) constituted the largest scientific periodical issuing ICP manuscripts during the period covered by this paper. In terms of methodology employed in ICP studies, researchers applied not only a single traditional technique but also a variety of research methods. Lastly, trends were identified within ICP studies in which six research topics are grouped and which, indeed, predict the future trends.

Although much effort was employed to view the research trends revealed in ICP, this work however, cannot be said to be totally comprehensive and exhaustive regarding the number of manuscripts reviewed. Attention is drawn to the fact that publication retrieval merely involved two journal databases; it is possible that some relevant articles have unconsciously been overlooked. Furthermore, the choice of search codes may also have caused inaccuracy in searching the target. Intensive research endeavour is therefore advocated, to further study this aspect. 


\section{Acknowledgements}

This study was funded by The Ministry of Research, Technology and Higher Education, Republic of Indonesia. Acknowledgements are given to Universitas Bung Hatta, PadangIndonesia and The Hong Kong Polytechnic University, for their support. The authors would like to express gratitude to Mrs. Elaine Anson for her contribution to proof reading of this manuscript.

\section{References}

Abdul-Aziz, A.R., 1991. Global strategies of construction firms. PhD. University of Reading, UK.

Abdul-Aziz, A.R., 1994. Global strategies: a comparison between Japanese and American construction firms. Construction Management and Economics, 12(6), pp.473-84. doi: http://dx.doi.org/10.1080/01446199400000059

Abdul-Aziz, A.R. and Wong, S.S., 2010. Exploring the internationalization of malaysian contractors: The international entrepreneurship dimension. Construction Management and Economics, 28(1), pp.51-61. doi: http://dx.doi.org/10.1080/01446190903460680

Aghaei Chadegani, A., Salehi, H., Yunus, M.M., Farhadi, H., Fooladi, M., Farhadi, M. and Ale Ebrahim, N., 2013. A comparison between two main academic literature collections: Web of Science and Scopus databases. Asian Social Science, 9(5), pp.18-26. doi: http://dx.doi.org/10.5539/ass.v9n5p18

Arditi, D. and Gutierrez, A.E., 1991. Performance of US contractors in foreign markets. Construction Management and Economics, 9(5), pp.431-49. doi: http://dx.doi.org/10.1080/01446199100000033

Ashley, D.B. and Bonner, J.J., 1987. Political risks in international construction. Journal of Construction Engineering and Management, 113(3), pp.447-67. doi: http://dx.doi.org/10.1061/(ASCE)0733-9364(1987)113:3(447)

Bon, R., 1992. The future of international construction: secular patterns of growth and decline. Habitat International, 16(3), pp.119-28. doi: http://dx.doi.org/10.1016/0197-3975(92)90068-A

Chan, E. and Tse, R., 2003. Cultural Considerations in International Construction Contracts. Journal of Construction Engineering and Management, 129(4), pp.375-81. doi: http://dx.doi.org/10.1061/(ASCE)0733-9364(2003)129:4(375)

Chau, K.W., 1997. The ranking of construction management journals. Construction Management and Economics, 15(4), pp.38798. doi: http://dx.doi.org/10.1080/014461997372953

Chen, C. and Messner, J., 2011. Characterizing entry modes for international construction markets: Paving the way to a selection model. Engineering, Construction and Architectural Management, 18(6), pp.547-67. doi: http://dx.doi.org/10.1108/09699981111180872

Dikmen, I. and Birgonul, M., 2004. Neural Network Model to Support International Market Entry Decisions. Journal of Construction Engineering and Management, 130(1), pp.59-66. doi: http://dx.doi.org/10.1061/(ASCE)07339364(2004)130:1(59)

Dikmen, I. and Birgonul, M.T., 2006. An analytic hierarchy process based model for risk and opportunity assessment of international construction projects. Canadian Journal of Civil Engineering, 33(1), pp.58-68. doi: http://dx.doi.org/10.1139/105-087.

Gay, L.R., Mills, G.E. and Airasian, P.W., 2011. Educational research: Competencies for analysis and applications. Pearson Higher Ed.

Gunhan, S., 2003. Foreign market entry decision model for construction companies. PhD. Illioni Institute of Technology, Chicago, US.

Gunhan, S. and Arditi, D., 2005a. Factors affecting international construction. Journal of Construction Engineering and Management, 131(3), pp.273-82. doi: http://dx.doi.org/10.1061/(ASCE)0733-9364(2005)131:3(273)

Gunhan, S. and Arditi, D., 2005b. International expansion decision for construction companies. Journal of Construction Engineering and Management, 131(8), pp.928-37. doi: http://dx.doi.org/10.1061/(ASCE)0733-9364(2005)131:8(928)

Guz, A. and Rushchitsky, J., 2009. Scopus: A system for the evaluation of scientific journals. International Applied Mechanics, 45(4), pp.351-62. doi: http://dx.doi.org/10.1007/s10778-009-0189-4

Halpin, D.W., 1990. International competition in construction technology. Journal of Professional Issues in Engineering, 116(4), pp.351-59. doi: http://dx.doi.org/10.1061/(ASCE)1052-3928(1990)116:4(351)

Han, S.H. and Diekmann, J.E., 2001a. Making a risk-based bid decision for overseas construction projects. Construction Management and Economics, 19(8), pp.765-76. doi: http://dx.doi.org/10.1080/01446190110072860

Han, S. and Diekmann, J., 2001b. Approaches for Making Risk-Based Go/No-Go Decision for International Projects. Journal of Construction Engineering and Management, 127(4), pp.300-08. doi: http://dx.doi.org/10.1061/(ASCE)07339364(2001)127:4(300)

Han, S., Diekmann, J., Lee, Y. and Ock, J., 2004. Multicriteria Financial Portfolio Risk Management for International Projects. Journal of Construction Engineering and Management, 130(3), pp.346-56. doi: http://dx.doi.org/10.1061/(ASCE)0733-9364(2004)130:3(346)

Han, S., Park, S., Kim, D., Kim, H. and Kang, Y., 2007. Causes of Bad Profit in Overseas Construction Projects. Journal of Construction Engineering and Management, 133(12), pp.932-43. doi: http://dx.doi.org/10.1061/(ASCE)07339364(2007)133:12(932) 
Han, S.H., Diekmann, J.E. and Ock, J.H., 2005. Contractor's risk attitudes in the selection of international construction projects. Journal of Construction Engineering and Management, 131(3), pp.283-92. doi: http://dx.doi.org/10.1061/(ASCE)0733-9364(2005)131:3(283)

Hastak, M. and Shaked, A., 2000. ICRAM-1: Model for International Construction Risk Assessment. Journal of Management in Engineering, 16(1), pp.59-69. doi: http://dx.doi.org/10.1061/(ASCE)0742-597X(2000)16:1(59)

Hawk, D., 2006. Conditions of Success: a platform for international construction development. Construction Management and Economics, 24(7), pp.735-42. doi: http://dx.doi.org/10.1080/01446190600658966

Holt, G., 2010. Contractor selection innovation: examination of two decades' published research. Construction Innovation, 10(3), pp.304-328. doi: http://dx.doi.org/10.1108/14714171011060097

Howard, G.S., Cole, D.A. and Maxwell, S.E., 1987. Research productivity in psychology based on publication in the journals of the American Psychological Association. American Psychologist, 42(11), p.975. doi: http://dx.doi.org/10.1037/0003-066X.42.11.975

Jaafari, A., 1984. Criticism of CPM for project planning analysis. Journal of construction engineering and management, 110(2), pp.222-33. doi: http://dx.doi.org/10.1061/(ASCE)0733-9364(1984)110:2(222)

Jung, W., Han, S. and Lee, K., 2012. Country Portfolio Solutions for Global Market Uncertainties. Journal of Management in Engineering, 28(4), pp.372-81. doi: http://dx.doi.org/10.1061/(ASCE)ME.1943-5479.0000099

Jung, W., Han, S., Park, H. and Kim, D., 2010. Empirical Assessment of Internationalization Strategies for Small and Medium Construction Companies. Journal of Construction Engineering and Management, 136(12), pp.1306-16. doi: http://dx.doi.org/10.1061/(ASCE)CO.1943-7862.0000237

Kapila, P. and Hendrickson, C., 2001. Exchange Rate Risk Management in International Construction Ventures. Journal of Management in Engineering, 17(4), pp.186-91. doi: http://dx.doi.org/10.1061/(ASCE)0742-597X(2001)17:4(186)

Ke, Y., Wang, S., Chan, A. and Cheung, E., 2009. Research Trend of Public-Private Partnership in Construction Journals. Journal of Construction Engineering and Management, 135(10), pp.1076-86. doi: http://dx.doi.org/10.1061/(ASCE)07339364(2009)135:10(1076)

Kim, D., Ashuri, B. and Han, S., 2013. Financial Valuation of Investments in International Construction Markets: RealOptions Approach for Market-Entry Decisions. Journal of Management in Engineering, 29(4), pp.355-68. doi: http://dx.doi.org/10.1061/(ASCE)ME.1943-5479.0000152

Ling, F.Y.Y., Ibbs, C.W. and Kumaraswamy, M.M., 2005. Enablers that help foreign architectural, engineering, and construction firms win construction contracts in China. Journal of Management in Engineering, 21(2), pp.63-69. doi: http://dx.doi.org/10.1061/(ASCE) 0742-597X(2005)21:2(63)

Lu, W., Li, H., Shen, L. and Huang, T., 2009. Strengths, Weaknesses, Opportunities, and Threats Analysis of Chinese Construction Companies in the Global Market. Journal of Management in Engineering, 25(4), pp.166-176. doi: http://dx.doi.org/10.1061/(ASCE)0742-597X(2009)25:4(166)

Mawhinney, M., 2001. International Construction. London: Blackwell Science Ltd. doi: http://dx.doi.org/10.1002/9780470690628

Ngowi, A.B., Pienaar, E., Talukhaba, A. and Mbachu, J., 2005. The globalisation of the construction industry - a review. Building and Environment, 40(1), pp.135-41. doi: http://dx.doi.org/10.1016/j.buildenv.2004.05.008

Osei-Kyei, R. and Chan, A.P., 2015. Review of studies on the Critical Success Factors for Public-Private Partnership (PPP) projects from 1990 to 2013. International Journal of Project Management, 33(6), pp.1335-46. Doi: http://dx.doi.org/10.1016/j.ijproman.2015.02.008

Ozorhon, B., Arditi, D., Dikmen, I. and Birgonul, M., 2008. Implications of Culture in the Performance of International Construction Joint Ventures. Journal of Construction Engineering and Management, 134(5), pp.361-70. doi: http://dx.doi.org/10.1061/(ASCE)0733-9364(2008)134:5(361)

Ozorhon, B., Dikmen, I. and Birgonul, M., 2006. Case-Based Reasoning Model for International Market Selection. Journal of Construction Engineering and Management, 132(9), pp.940-48. doi: http://dx.doi.org/10.1061/(ASCE)07339364(2006)132:9(940)

Shen, L., Wu, G. and Ng, C., 2001. Risk Assessment for Construction Joint Ventures in China. Journal of Construction Engineering and Management, 127(1), pp.76-81. doi: http://dx.doi.org/10.1061/(ASCE)0733-9364(2001)127:1(76)

Simkoko, E., 1992. Managing international construction projects for competence development within local firms. International Journal of Project Management, 10(1), pp.12-22. doi: http://dx.doi.org/10.1016/0263-7863(92)90068-K

Tang, L.C.M., Atkinson, B. and Zou, R.R., 2012. An entropy-based SWOT evaluation process of critical success factors for international market entry: A case study of a medium-sized consulting company. Construction Management and Economics, $\quad 30(10), \quad$ pp.821-34. doi: $\quad 10.1080 / 01446193.2012 .697180 . \quad$ doi: http://dx.doi.org/10.1080/01446193.2012.697180

Yi, W. and Chan, A.P., 2013. Critical review of labor productivity research in construction journals. Journal of Management in Engineering, 30(2), pp.214-25. doi: http://dx.doi.org/10.1061/(ASCE)ME.1943-5479.0000194

Yuan, H. and Shen, L., 2011. Trend of the research on construction and demolition waste management. Waste management, 31(4), pp.670-79.

Zhang, X., 2011. Social risks for international players in the construction market: A China study. Habitat International, 35(3), pp.514-19. doi: http://dx.doi.org/10.1016/j.habitatint.2011.02.005. 